\title{
AFFECTIONS OF SPEECH IN THE INSANE.
}

BY T. H. Kellobig, M. D.

Physician in Charge, Sanford Hall, Flushing, N. Y.

Speech, in the opinion of some, was the last and best gift of the great creator to man; while according to the view of othere, it is a faculty that has been perfected through countless ages of evolution of the human intellect. In any case it is this facultas signatura - this wonderful ability to clothe thoughts in significant words - that preëminently distinguishes man from all other living creatures.

It is strange that the literature of the history and varieties of languages should be so immense, and that so little should ever have been written about the disorders of speech. It is true that the oldest medical authors did not fail to allude to such disorders, but they did not attempt to explain them, owing doubtless to the inherent difficulties of the subject. In fact, it is only modern medical science, and more especially new physiological and anatomical facts, which have enabled recent medical writers to throw a clear light on the more important disorders of speech.

So far as affections of speech in the insane are concerned, their study has only just begun; and one must enter upon their survey almost as upon terra incognita, so meagre is the literature of the subject. This paper is offered, therefore, merely as an introduction to an interesting and difficult subject. In order to facilitate its study an arrangement into two main groups has been made.

The first group inciudes affections of speech due to organic brain lesions involving the ganglionic centres, or conducting nerve tracts, which serve the purposes of speech, as follows:

1, Paretic speech; 2, Alcoholic and other toxic speech disorders; 3, Scanning speech ; 4, Organic dementia with aphasia in its various forms; 5 , Defects of speech in idiocy and imbecility.

The second group consists of affections of speech which are the immediate outcome of the physical disease. These are as follows:

1, The formation of new words; 2, Echo speech; 3, Rhyming and repetitive speech; 4, Histrinnic speech, including gesture language ; 5, Retardea and accelerated speech; 6, Muteism; 7, Abulic speech.

The consideration of these affections will now proceed in the order above adopted. 
Certain physiological and anatomical facts in this complex subject of speech and its mechanism have been sufficiently established by many experiments and repeated pathological observations. It is now known that there are cortical speech centres, that there are articulatory centres in the pons and medulla, and that these are in convection with the origin of the nerves innervating the muscles concerned in articulation. Now lesions in any of these regions may impede or destroy the power of speech, and they are uni. formly present in all the affections of this tirst group of which paretic specch is the type. The chief characteristics of paretic speech are retardation, indistinctness, repetition of syllables or words, failure of lingual or labial sounds, tremor of voice, nasal intonation and explosive utterance. They are seldom all present in the same patient.

The slowness and hesitation of speech are often the result of cortical lesions, which give rise to diminished attention and mem. ory and general retardation of all psychical acts. The drawling in other instances may be attributed to impeded transmissions of cortical and volitional impulses to the basal articulatory centres, or in tabetic cases to lesions of the origin of the nerves of speech.

The repetition aud stuttering are also to be ascribed to cortical and psychical lesions rather than to those of the basal phonic centre. In the early stage it is only under emotional excitement that the balbuties is wont to appear, and this would also seem to show that it is of psychical origin. The failure in the lingual and labial consonants arises from incöordination of the muscles of the tongue and lips and is highly characteristic. The unevenness and tremor of the voice proceed from incöordination and insufficient action of the diaphragm, intercostals, and of all themuscles which tend to produce an even pressure of the outgoing vocal current of air. The nasal intonation is the result of relaxation of the soft palate and of the nasal and pharyngeal meinbranes. The sudden interruption of voice followed by explosivo utterances is caused by spasmodic glot tic closure. All these various affections are exaggerated under tmotional excitement. In ascending cases of general paralyris the speech is not apt to be affected until the ascending spinal lesions have involved the nervous centres of the medulla, whence spring the motor speech innervations. It can readily be understood, therefore, what a varied pathology these affections of paretic speech may have. The lesions may be in the cortex, in the lenticular necleus and internal capsule, in the puns or 
the basal articulatory centres, or at the central origin of the motor nerves of specch.

A hasty glance must now be given to the next topic in order, which is alcoholic and other forms of toxic speech. The defects of articulation here are not due to incöordination, but to notor impairment and to actual failure of innervation. In other words, the specch of general paralysis is ataxic, while alcoholic speech is truly paretic. In alcoholic speech there may be simply a fine tremor of the tongue and lips, causing impaired articulation. In other cases there are decided spasms of these organs of speech, which give rise to obvious defects of pronunciation. In the most complete cases of alcoholic dementia there is a fully developed paresis of the tongue and lips. Alcoholic speech is ordinarily accompanied by more general convulsive facial movements than are found in general paresis, and there is also early present a peculiar hoarseness valuable in the differential diagnosis of alcoholic from paretic specch, and the retardation of speech is often greater in the alcoholic than in the paretic dement. In the other forms of toxic insanities, from lead, mercurs, opium, chloral, and a host of deleterious agents capable of seriously damiging the nervous centres, the speech may be affected in many ways.

The writer has seen tremor, retardation, stuttering and a variety of minor affectiuns of speech from these causes. In some of these instances the affections of speech are functional and in others they are due to actual lesions of nerve cells and of conducting fibres. In this connection is to be mentioned also the influence on brain centres (already weakened in insanity) of various bloot poisons Thus acute intercurrent diseases and diathetic states in the insane derange spcech in various degrees. Thus arise temporary aphasic disorders following zymotic fevers, aphonia in phthisical and scanning utterance in syphilitic insanity, choreic speech in rheumatic and sudden temporary loss of language in podagrous cases.

In regard to the action of fevers it is well authenticated that demonts who have been mute for years will resume speech under the feverish stimulation of cortical centres. It is also no longer a matter of doubt that the same class of patients may regain speech and even a certain degree of lucidity during the last hours of their life. Scanning speech in its most typical form is found only in cases complicated with multiple cerebro-spinal salerosis.

There is a species of scanning speech, however, found both in paretic and alcoholic dementia. Next in order are the speech affections of organic dementia and its various forms of aphasia. 
Organic dementia as here understood includes all forms of mental disease from embolism, thrombosis, encephalitis, tumors, and other gross lesions of brain substances.

A common form is cerebral hemorrhage with hemiplegia and more or less permanent mental disorder.

It is in connection with such gross braiu lesions that the different forms of aphasia appear and as there are no affections of speech of greater interest they are here passed briefly in review.

In the first place there is motor aphasia with a patbology of lesions in the left, third frontal convolution. It consists in a loss of memory of the motor coördinations essential for the ntterance of words. The patient has forgotten how to pronounce, and can neither speak nor can be repeat words spoken in his presence, though he can understand what is said to him. In other cases there may be loss of recollection of the manual efforts necessary to form letters. This agraphia renders the patient unable to write or copy that which is written, and is probably due to lesions of the posterior part of the second frontal convolution.

There is also among the insane a purely amnesic pseudo. agraphia not connected with any local brain disease. In these cuses the patients may invent a sort of bandwriting of their own for the one which they have forgotton. They may still be able to copy writing. This is not the same state as that of certain dements who can only write when the words are dictated to them, and may not be able to construct sentences of their own accord.

When the lesions in organic dementia involve the posterior part of the first and second temporal convolutions word-deafness may be produced. This affiection consists in inability to recall the sounds of words or to recognize these sounds when made by otbers, so that the patient cannot conduct or understand conversation.

As a matter of differential diagnosis it is important that this affection should be understood, as two instances are on record in which patients suffering from word deafness were mistaken for insane persons, and treated accordingly. When the lesions involve the inferior parietal convolution and the angular gyrus the patient may have word-blindness, that is to say, he forgets the form of words and he can neither write nor read writing.

Both in organic dementia and in general paralysis of the insane there is another form of aphasia which consists in the loss of the memors of sensory perceptious, and in the inability to recognize 
the nature of things through the ordinary channels of the special senser. The speech ot course is affected in proportion as the cortical residua of past sensory perceptions are destroyed by disease.

Thus a patient may look at a bell and fail to recognize it, and may call it by some entirely different word. If the bell is made to sound, however, be may through the revival of past auditory perceptions recall the true nature of the object. In this instance the patient has psychical blindness. Likewise if the patient were to hear a familiar musical instrument and not recognize what it was be would be said to be psychically deaf. Or if he fail to recoguize familiar odors be would be said to have psychical anosmia.

In like manuer the memory of the visual, auditory, olfactory, and tactile perceptions for different objects may be individually or collectively lost, and cause a corresponding confusion or loss of speech. It is to be hoped that the diagnosis and clinical study of these cases of apraxia may be more frequently made in the future, and that autopsical examinations may throw additional light on the subject of their pathology.

The alienist must be familiar with all these speech affections lest he should mirtake them for an essential part of the insanity attending gross brain lesions, and fail to recognize convalescence, and the proper time to begin the reëducation of the patient as regards speech. Finally in this group of affections of speech from brain lesions are those decided defects or even entire absence of language from early arrest of ccrebral development. In the congenital forms of idiocy, when the brain has not attained more than an embryonic growth, there is absence of speech or only a few balf articulated sounds are present.

In microcephalic cases there is a possibility of education of the powers of speech so that simple wants may be expressed.

In idiocy acquired at three or four years, or later, there may be a childish command of language or in ixceptional cases an almost incessant and trivial use of speech. Under the influence of music or of sudden emotions idiots, otherwise silent, will speak a few words. There is also in idiocy as in chronic states of insanity the automatic repetition of the same words for hours or days togetber, as well as the parrot-like repetition of words with which no idea is connected.

Imbecility also presents a variety of defects of specch, some 
due to physical malformations of speech organs, though the majority proceed from native insufficiency of brain development. Not a few imbeciles have quick memories for details and enough ideas ard imagination to talk incessantly with entire lack of inhibition of thought. The opposite state of this logorrbœa is also found in imbeciles who speak only on rare occasious.

Both idiots or imbeciles use sometimes old words in a new sense or invent words of their own to express their wants or their ideas. This is analogous to that peculiar individual use of sounds or words often made by very young children. In some families successive children will use the same words in like manner, or each child may have its own little language and may even retain some of these peculiarities until it is grown. The whistling, clicking, sucking, blowing, hissing and grunting sounds made by these automatic beings with only half developed intellects are very similar to the many inarticulate cries and sounds made by patients in the terminal stages of insanity. Echo, speech and gesturelanguage are also commouly observed in these originally defective patients. In accordance with the previous division the first derangenent of speech in the second group to which attention is now called is the formation and use of new words. It is a fact of common remark that the insane often make a striking and original use of language. It is also a point of less frequent observation that they use words in an entirely new sense. There comes a time, however, when neither of these resources is sufficient to express the weird fancies or the strange emotions which crowd the mind diseased, and some new collocation of sounds is often uttered and repeated, and finally comes to represent some, more or less, definite thing.

Only a few of the queer vocal utterances of maniace, more especially, ever attain to the dignity of new words. They often continue for hours making sounds, more or less articulate, which have only a momentary relation to their fleeting fancies; but every now and then they hit upon a combination of sounds which chime in happy accord with some crazy idea, and by repetition come to represent it. It is well known that tastes, odore, and especiall 5 colors, arouse agreeable or disagreeble ideas in the insane. Likewise, some sounds rather than others suggest pleasing things, and are by preference adopted in their new vocabulary. Just as in the healthy mind, the fixed principle of association of ideas governs all verbal processes, so in the mind diseased there is a 
definite pathological law which controls this formation of new words. Sometimes there is a certain relation between the sense and the sound of the new words which seem to have been suggested in accordance with the law of onomatopœia. Words thus newly formed by the insane are often used, more or less, consistently for months or even for years. More than twenty years ago there came under the writer's care an intelligent captain who chiefly from the hardships of war lost his reason. For a long time his chief delusion was that he was Jesus Christ. Later he developed a variety of grandiose insane ideas. He was orderly and the very pink of politeness, and he remained employed as a reliable copyist. He coined a great variety of new words with open vowel sound freely interspersed with the letter $R$, which he rolled vigorously. When walking alone he would speak these sonorous phrases in a most earnest tone of voice, and he claimed that they were a means of communication between him and the Almighty. This man is still living. He has married, settled down and raised a large family. He has the same religious. delusions, and he still speaks aloud to himself words which he coined twenty years ago.

It may be said finally that this formation of new words is most common in imbecility, in paranoia, and in chronic mania.

The next point to be considerell is echo speech. This is the automatic repetition of words spoken in the presence of the patient and with which he associates no definite conception. The automatic repetition of words is most common in congenital states of mental weakness or in cases of secondary mental enfeeblement. Some terminal dements never speak except to thus echo back words pronounced before them.

Occasionally there is a case in which all spontaneity and free speech have not disappeared and with them it is not uncommon to find an echolalia not of words simply, but of entire sentences. A number of cases have been observed by the writer in which no satisfactory response could be elicited by questions, but all short categorical phrases addressed to the patient were automatically re. peated "verbatim et literatim."

Probably the explanatory principle involved here is simply that of imitation, which exists so markedly in all low forms of intelligence. At any rate this echo speech is very common in all kinds of early arrest of mental development, as well as in dementia, paranoia and bysterical and epileptic insanity. 
In patients who will only communicate by writing a species of echolalia is sometimes found, in that questions put to them are simply repeated in writing. This was the case of a deaf mute capable of communication if he chose, who often would only re. write the questions put to him.

Rhyming and repetitive speech also now claim a brief notice. By rhyming is not meant the poetical composition of the insane, but rather the habit of expressing the most commonplace things in phrases which rhyme. Versification and rhythm as a rule are out of the question here, and words that have a like jingle are interjected at random in the conversation. Now and then, however, in a patient of some native talent for verse making, there will be developed under abnormal cortical excitation a most axtonishing fluency in rhyming. Rhyming is most apt to be found in pubescent insanity, in paranoia and in chronic mania.

Repetitive speech, unlike echo speech, is independent of outward auditory impressions and consists in the repeated utterance of the same phrases or words, which inay or may not convey a definite meaning to the listener, though tney usually are connected with some idea in the mind of the patient. It is probsbly a morbid irritation of cortical speech centres with a narrowell range of thought that shus impels the patient to repeat over and over again the same words or sentences for hours or even days together. This condition must not be confounded with the constant repetition of prayers in patients suffering from religious fears or the reiteration of harassing delusions. The most typical instances of repetitive speech are apt to be found in maniacal stztes.

It is of interest to mention also in this connection the spelling habit of speech among the insane. The words are spelled before they are pronounced. Sometimes each syllable is given a distinct separate utterance before the word is pronounced as a whole, and again the words are rapidly spelled and the entire sentence then spoken. This affection of speech sometimes coincides with maniacal recurrences and is likely connected with pathological irritation of cortical speech centres.

The next point noted in the division of this subject is histrionic speech, including peculiarities of intonation and gesture language. Like genuine cases of ecstacy and trance, the typical histrionic state in the insane is exceeding rare. Out of many thousands of cases of mental dieease which have been under the writer's care, it has bsen his good fortune to witness only a few instances of in- 
sane histrionism. In these, however, the elocution was so sustained and remarkable, and the acting of such a highly dramatic character as to excite the forcible conviction that even Shakespeare, in his most extreme delineations of insanity, had not overstepped the mark, but had simply held the mirror up to nature. In many of the acute forms of insanity there is also a transitory acting out of the strong feelings which agitate the mind. Anger, hope, fear and hatred, are frequently depicted in the insane countenance as well as by the voice and gestures. The emotional changes of the voice are so sudden, in keeping with the rapid succession of emotions, as to differ from any changes of speech heard in health, and to thus furnish a valuable means of detecting malingerers, who almost invariably fail in attempting to imitate these emotional rocal effects, however well they may succeed in other regards.

It is needless to enlarge on the varieties of histrionic speech in the insane. There are tragedians, conedians and clowns among them. There is the acute melancholiar, frenzied with delusions of loss of friends, fortune and honor, breaking out finally in the most tragic speecb, with arm uplifted for a homicidal or suicidal act. There is the chronic maniac-self-styled queen of heaven, it may be, with mincing mien and affected loftiness of speech, condescending in her tones of voice, fantastically arrayed, and acting the part of the veriest comedian. And finally comes the clown in the form of some balf imbecile or partial dement, grimacing, gesticulating, whistling, grunting, sputtering and going through all the motions of the buffoon. In this connection also must be considered the gesture language of the insane. Their pantomime is often per fect.

Gesture, in fact, is more primitive than speech as a means of expression, and it is often a resort when words fail to express the rapid flight of emotions in the insane. It remains also when speech is exhausted. Witness the outbreak of an attack of acute delirious mania. Listen to the rapid speech as it is poured forth in loud words-listen again later, as the words crowd upon one another too rapidly for distinct pronunciation, and again as the hoarse voice and dry lips give forth only half articulated sounds, and still later when the patient is voiceless, but not speechless, for he still articulates in a whisper, and finally when this fails then the gesture language becomes the means of expression. In case of voluntary mutism with refusal to write, gesture language may be for months at a time the only method of communication. 
The speech of the insane is strikingly affected so far as intonation is concerned, but time will not permit more than a few lines as to these peculiarities of intonation. It is well known that there is a music of speech as well as of song - that the voice glides up and down on the musical scale of speech just as really as it does on the diatonic scale of song. Indeed, every pure vowel sound in speech is compoied of a grounil-tone, rainforced by harmonic overtones. It is this fact, together with the rising, falling and circumflex intenations which conititutes the musical nature of the speaking voice. The experiments of Helmboltz showerl that the open Italian had more harmonic overtones than any other vowel sound, and this is one explanation of the preference universally accorded to Italian as the language of song. Now in the insane not only is there impurity in the fundamental vowel tones, but the inflections are abrupt, unuatural and disagreeable, and hence arise the lo:s of musical quality of voice and a peculiar harshness which is highly diagnostic. Frequently the rising and falling inflections almost entirely disappear and there remains a harsh monotone. In some cases the huskiness is due to relaxation and lack of innesvation of the vocal organs.

Sometimes the insane adopt a sing song delivery and again they may intone all that they say. Passing over many minor defects in articulation and vocal mannerisms haste is made to say something of retarded and accelerated speech. In all forms of mental depression there is apt to be increased inhibition of ideas and retarded speech-rate. In all states of original psychical defect and of secondary mental enfecblement likewise there is also as a rule slowed speech.

There is a certain time necessary for a word addressed a patient to provoke a response. Il takes time for the auditory impression to reach the cortical acoustic centres-time for conscious thought as to the answer to be given, and finally time for the words willed to be spoken to be actually emitted by the mechanism of speech. The delay may be in any of these cbannels in retarded speech, though it is more often in the conceptive than in the emissive sphere. Numerous observations by Beran Lewis and others have shown that the reaction time for acoustic stimuli is from 12.100 to 18.100 of a sccond in heslth, whereas among the insane it is of ten increased to 30-100 of a second.

Alcoholic and paretic dements ordinarily furnish the most decided retardation of speech-rate, though the most typical case that 
the writer ever saw of this speech affection was in an epileptic case of insanity.

Accelerated speech like increased thought-rate is found chiefly in maniacal cases. In them all inhibition is wanting and thoughts surge into consciousness without let or hindrance and are uttered as fast as the organs of speech can possibly act. English orators having the most rapid diction are said to average two hundred words per minute. It is rafe to say that some maniacs surpass this degree of rapidity of utterance.

In striking contrast with those patients who speak volumes in a short time are those who never utter a word. Mutisin is however a rarer condition than logorrhoe:ı. A part from terminal dementia stuporous states, melancholia attonita, acute primary dementia, and idiocy, mutism is uncommon. Occasionally a patient under the influence of delusions will conilemn himself to obstinate silence for months or even years at a time and may then resume speech as usual. But it is difficult for one in full possessiou of his powers of speech to refrain from using them. it is indeed astonishing that patients who have been mute for years will resume speech suddenly. Esquirol mentions a case that began to speak again after 30 years of silence.

Finally there is to be noticed in this group of affections of speech which are the immediate outcome of the psychical disease, abulic speech. It is due to morbid instinctive tendencies to commit improprieties of speech and is immediately associated with loss of inhibition. The patient has an impellent idea to impudence, profanity, or obscenity, and has not sufficient self-control to resist it. They are fully conscious of the nature of their offensive speech and are often immediately after the act penitent and even bitterly self reproachful. Still their outbreaks continue in many cases with about the same regularitly as epileptic explosions. This affection is to be distinguished from the objectional language of acute and chronic maniacs or dements or of any other class of patients not fully aware of the nature of that which they utter. The impellent idea may relate to the pronunciation of one or more words, or the tendency may be to seize on every opportunity to outrage the decencies of speech. In one instance under the writer's observation the offensive words were interjected suddenly without any connection with the conversation, which was then carried on without a break as if nothing unusual had been said.

It may be said that abulic speech is most common in hysterical 
and epileptic insanity, and in paranoia and the instinctive insanity of childhood. Finally the involuntary speech and ejaculations which occur in choreic insanity deserve to be mentioned. There is a psychical as well as a muscular chorea in these cases and words escape voluntary control and are often thus uttered to the chagrin of the patient.

If in thus passing bastily in review some of the chief affections of speech in the insane this article shall lead others to a more extended study of this subject, it will have attained its chief object. 